\title{
Functional and radiological outcomes after treatment with custom-made acetabular components in patients with Paprosky type 3 acetabular defects: short-term results
}

Michael S. Gruber ${ }^{1}$, Michael Jesenko², Julia Burghuber ${ }^{1}$, Josef Hochreiter ${ }^{3}$, Peter Ritschl ${ }^{2}$ and Reinhold Ortmaier ${ }^{3,4^{*}}$ (i)

\begin{abstract}
Background: Severe acetabular defects require special treatment with either impaction bone grafting, metal augmented cups or cup-cage constructs. Even these options are often not adequate, especially in hips with Paprosky type 3 defects with loss of anterior and posterior columns. This study investigates the clinical and radiological outcomes of custom-made acetabular components (๑ Materialise NV, Leuven, Belgium) for Paprosky type 3 defects.

Methods: Sixteen patients were eligible for this trial, nine of whom agreed to be included. All of them completed one year of follow-up. The Harris hip score and the Oxford hip score were used to compare pre- and postoperative functional outcomes. Radiological follow-up comprised anteversion and inclination of the implanted cup and offset measurements in both hips (femoral, medial, ischial offset and center of rotation). Statistical analyses were performed with IBM SPSS Statistics.

Results: The mean follow-up time of the nine patients was 12.2 months (range: 10-18). The Oxford hip score and Harris hip score improved from 19.8 and 50.1 to 29.4 and 68.8 , respectively $(p=0.009$ and 0.01$)$. There were complications in three cases (33.3\%), which led to one re-revision (11.1\%). Radiologic follow-up showed restoration of the height of the center of rotation and of the global offset. Significant difference was detected in the femoral offset.
\end{abstract}

Conclusions: The functional and radiological outcomes are promising. However, long-term outcomes still need to be examined.

Level of evidence: Therapeutic Level IV.

Keywords: CTAC, 3D-printed prosthesis, Revision surgery, Severe acetabular bone loss, Custom-made acetabular component, Total hip arthroplasty

\footnotetext{
* Correspondence: r.ortmaier@gmail.com

${ }^{3}$ Department of Orthopedic Surgery, Ordensklinikum Barmherzige

Schwestern Linz, Vinzenzgruppe Center of Orthopedic Excellence, Teaching

Hospital of the Paracelsus Medical University Salzburg, Linz 4020, Austria

${ }^{4}$ Institute for Sports Medicine, Alpine Medicine and Health Tourism (ISAG),

Tirol Kliniken GmbH, Innsbruck and UMIT, Hall Austria, Innsbruck 6020, Tyrol,

Austria

Full list of author information is available at the end of the article
}

C C The Author(s). 2020 Open Access This article is licensed under a Creative Commons Attribution 4.0 International License, which permits use, sharing, adaptation, distribution and reproduction in any medium or format, as long as you give appropriate credit to the original author(s) and the source, provide a link to the Creative Commons licence, and indicate if changes were made. The images or other third party material in this article are included in the article's Creative Commons licence, unless indicated otherwise in a credit line to the material. If material is not included in the article's Creative Commons licence and your intended use is not permitted by statutory regulation or exceeds the permitted use, you will need to obtain permission directly from the copyright holder. To view a copy of this licence, visit http://creativecommons.org/licenses/by/4.0/. The Creative Commons Public Domain Dedication waiver (http://creativecommons.org/publicdomain/zero/1.0/) applies to the data made available in this article, unless otherwise stated in a credit line to the data. 


\section{Background}

The number of total hip arthroplasties (THAs) has increased in recent decades, and a further increase in incidence is predicted [1-3]. The reasons for this increase are multifactorial and comprise an increasing incidence of THA in younger as well as in older [3].

However, with an increasing number of primary THAs, the absolute number of revisions will automatically increase, and orthopedic surgeons will be increasingly forced to deal with revision surgeries.

Reasons for revisions are dislocation/instability (22\%), mechanical loosening (20\%), infection (15\%) and implant failure $(10 \%)$ [4]. In terms of revision, extensive acetabular defects are one of the most challenging situations for surgeons. While many contained defects can be managed with the use of standard cups, uncontained extensive defects require other strategies. Acetabular defects can be approached mainly with three methods, namely, impaction bone grafting (IBG), metal augmented cups or cup-cage constructs [5].

IBG was first described by Hastings and Parker in 1975 [6], and initial reports showed high overall failure rates. Later, the Exeter and Nijmegen groups reported improved outcome with IBG and the usage of cemented cups $[7,8]$. The results also improved thanks to the use of cementless, porous-coated cups, which lead to improve bone integration $[9,10]$. However, this technique is limited by the severity of the defect, and the outcome is linked to the Paprosky type of defect [11].

Metal augments have been used for many years now. Tantalum is the material of choice. It can be shaped in a highly porous "foam", with low stiffness and high friction. These implants can be placed directly at the area of the defect and can restore the center of rotation (COR). However, as in IBG, metal-augmented implants need a certain amount of host bone to achieve sufficient fixation for integration [12].

For more severe defects or pelvic discontinuities, cupcage constructs are available. With the use of these stiff implants, Martin et al. reported relatively good outcomes and survivorship [13].

However, in regard to combined defects with anterior and posterior column deficiency, established implants do not provide satisfactory results in terms of COR position $[14,15]$.

As an alternative to the abovementioned methods, newly and specially designed custom-made triflanged acetabular components (CTACs) are on the rise. These can be produced and adapted for each unique acetabular defect based on preoperative CT images. The main goals of revision surgery for acetabular defects are to restore the biomechanics of the hip (COR), to achieve implant stability and to restore bone stock [16]. CTACs were developed to achieve implant stability and restore hip biomechanics in cases with severe bone loss. Although this method is quite expensive compared to the use of standard implants $[17,18]$, it may often be the only possible solution for THA revision.

The purpose of this retrospective cohort study was to evaluate the clinical and radiological results after treatment with CTAC cups for revision surgery in patients with severe Paprosky 3A and 3B acetabular defects.

\section{Methods}

In the period from April 2016 to April 2018, 16 patients received treatment with aMace (ㄷ Materialise NV, Leuven, Belgium) CTACs for revision THA with concomitant acetabular type 3A or 3B bone defects (Table 1). Of these sixteen patients, nine agreed to be included and followed up in this trial. Four patients were treated at the hospital "Ordensklinikum Linz GmbH Barmherzige Schwestern", and five patients were treated at the Orthopedic Hospital Gersthof. The reasons for revision surgery varied: seven patients received treatment because of aseptic loosening, and one patient each received treatment because of periprosthetic acetabular fracture and septic loosening. Before implantation, infection was excluded through preoperative intraarticular joint aspiration and evaluations of C-reactive protein (CRP) and white blood cell (WBC) count as well as clinical investigations. Additional intraoperative sonication of the dismantled implant and/or examination of five tissue samples verified correct preoperative diagnostics. Three of the nine surgeries were performed on the left hip and six on the right hip. All of the patients included were female, and the patients' age at the time of surgery was between 42 and 85 years (mean 69.3). The mean body mass index was $29.2 \mathrm{~kg} / \mathrm{m}^{2}$ (range: 19.8-42.1) (Table 2).

All patients who agreed to be included into this trial completed radiological and functional follow-up examinations (100\%). While clinical follow-up comprised preand postoperative evaluation of Oxford hip score (OHS) [20] and Harris hip score (HHS) [21], radiological follow-up included preoperative CT scans and postoperative conventional X-rays. Pre- and postoperative images were compared for implant migration and to determine the correction of the offset. Offset-measurement comprised femoral (femoral axis to center of inlay), medial (center of pelvis to center of inlay) and ilioischial (ilioischial line to center of inlay) offset as well as center of rotation (inter-teardrop line to center of inlay) and was performed with TraumaCad (Brainlab AG, Munich, Germany).

The mean follow-up was 12.2 months (range: 10-18). Radiological investigation showed one patient with Paprosky type 3A and 8 patients with Paprosky type 3B acetabular defects (Table 2). The patients who 
Table 1 Paprosky classification of acetabular bone loss - created according to Classifications In Brief - Paprosky Classification of Acetabular Bone Loss [19]

\begin{tabular}{|c|c|c|c|c|c|}
\hline Defect & Tear drop & Superior dome & Anterior column & Posterior column & Bone bed \\
\hline Type 1 & Present & No migration & Intact & Intact & Mild (> 50\% cancellous) \\
\hline Type 2A & Intact & $\begin{array}{l}\text { Mild migration } \\
<2 \mathrm{~cm} \text { superior }\end{array}$ & Intact & Intact & Moderate $(<50 \%$ cancellous $)$ \\
\hline Type 2B & Intact & $\begin{array}{l}\text { Mild migration } \\
<2 \mathrm{~cm} \text { superolateral }\end{array}$ & Intact & Intact & Moderate ( $<50 \%$ cancellous) \\
\hline Type 2C & Moderate destruction & $\begin{array}{l}\text { Mild migration } \\
<2 \mathrm{~cm} \text { medial }\end{array}$ & Disrupted & Intact & Moderate $(<50 \%$ cancellous $)$ \\
\hline Type 3A & Moderate destruction & $\begin{array}{l}\text { Severe migration } \\
>2 \mathrm{~cm} \text { superolateral }\end{array}$ & Intact & Moderate lysis & Severe $10-2$ o'clock loss (40-70\% sclerotic) \\
\hline Type 3B & Complete obliteration & $\begin{array}{l}\text { Severe migration } \\
>2 \mathrm{~cm} \text { superomedial }\end{array}$ & Disrupted & Severe lysis & $\begin{array}{l}\text { Severe } 9-5 \text { o'clock loss } \\
\text { (30\% sclerotic) }\end{array}$ \\
\hline
\end{tabular}

completed follow-up were hospitalized for a mean of 21.9 days $( \pm 6.3 \mathrm{SD})$.

Short-term follow-up was chosen due to the limited preexisting evidence and influence of the outcome on the applicability of the implant.

This study was approved by the ethics committee of the hospital "Ordensklinikum Linz GmbH Barmherzige Schwestern" (EKS 25/19). All patients provided informed consent.

\section{Preoperative evaluation and planning}

First, conventional X-rays in 2 planes (anterior-posterior and axial) were performed in the affected hip. Implant positioning and loosening and fractures were documented.

Then, a CT scan following a special protocol provided by the company was performed. A 3D model of the acetabulum and the pelvis was then virtually conducted, and bone defects and fracture lines were identified. While acetabular bone loss was quantified and classified into the Paprosky score, bone quality was evaluated for fixation of the screws (Figs. 1, 11). An implant design based on the anatomical center of rotation, inclination, anteversion and bone preservation was proposed (Fig. 2). The implant consisted of porous augmentation and the plate, which were built as one part. A titanium alloy was

Table 2 Patient demographics of all patients available for follow-up

\begin{tabular}{ll}
\hline & aMace $(\boldsymbol{n}=\mathbf{9})$ \\
\hline Age (years/range) & $69.3 \pm 13.7$ \\
Sex (female/male) & $9(100) / 0(0)$ \\
Side (left/right) & $3(33.3) / 6(66.7)$ \\
BMl (kg/m²) & $29.2 \pm 6.9$ \\
Smoker (yes/no) & $1(11.1) / 8(88.9)$ \\
Paprosky (3A/3B) & $1(11.1) / 8(88.9)$ \\
\hline
\end{tabular}

Data are presented as the mean \pm standard deviation or absolute numbers (percentages) used for the triflanged acetabular cup and the defect filling trabecular augment (Ti6AI4V ELI). Screw length and direction as well as the diameter of the screws were chosen according to bone quality and remaining bone stock.

A preliminary planning report was provided to the surgeon and included instructions for preparation and reconstruction as well as a proposal for screw positioning and length. It was subsequently reviewed by the surgeon and updated to the surgeon's suggestions via web meetings for improvement. Production started after a final check and confirmation of the final planning report. The listed time for planning and production was 5 weeks ( 1 and 4 weeks, respectively). The implant came with a trial implant, bone model and custom drill guides. All components were delivered nonsterile and had to be sterilized at the hospital facility. Instruments, screws and cup/liner components were provided by the hospital.

\section{Surgical technique}

Surgery was performed following a standard protocol. Antibiotics were administered preoperatively. Tissue samples for sonication and microbial evaluation were harvested intraoperatively. The procedure was performed in the supine position, and a transgluteal approach was used. For the preparation of proper implant insertion, bone removal and clearance of some bone fragments, according to the planning report, were sometimes necessary, and gaps were filled with morselized allograft bone material afterwards. After bone bed preparation, the trial model of the implant was placed into the acetabulum to confirm implant seating and fitting. Then, the implant was brought in together with a custom drill guide. After drilling, the screw length was confirmed and compared to the planned screw length. After fixation of the acetabular component, a standard or dual mobility cup/liner component was cemented in the implant. The maximum size was predefined by the planning report. 


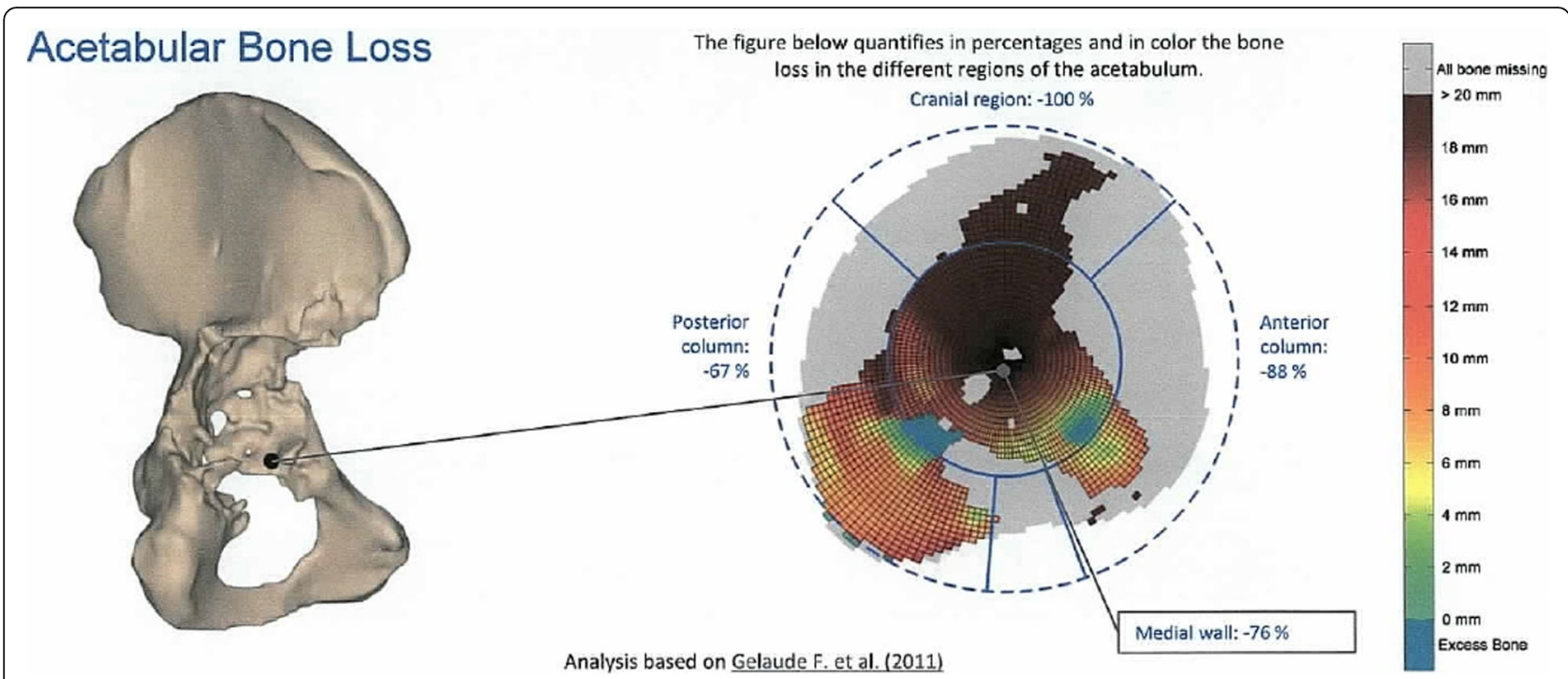

Fig. 1 Quantification of acetabular bone loss and assessment of bone quality. Source: planning report provided by Materialise NV, Leuven, Belgium. Permission from the copyright holder to publish the figure has been obtained

\section{Postoperative protocol}

Patients were mobilized immediately on the first postoperative day after drainage removal. Full weight bearing and full range of motion were allowed immediately after surgery in all patients.

\section{Statistics}

Statistical analyses were performed with IBM SPSS Statistics (Windows, 64 bit, version 23.0; IBM Corp., Armonk, NY, USA). Descriptive statistics were used to investigate patient characteristics. Pre- and postoperative OHS and HHS were compared using paired t-tests. Radiological differences between the treated side of the hip and the contralateral side were evaluated with descriptive statistics and paired t-tests. Statistical significance was reported as a $p$-value of $\leq 0.05$. There were no missing data. Patients who did not complete the followup examinations were declared as lost to follow-up and were excluded from the final analysis.

\section{Results}

Follow-up results showed an increase in postoperative scores compared to the preoperative assessment. Surgical treatment of patients with severe acetabular bone loss using aMace cups led to significant improvements in the OHS (preoperative median: 18, range: 11-43; postoperative median: 30 , range: $16-47 ; n=9 ; p=0.009$ ) and HHS (preoperative median: 53, range: 23-92;

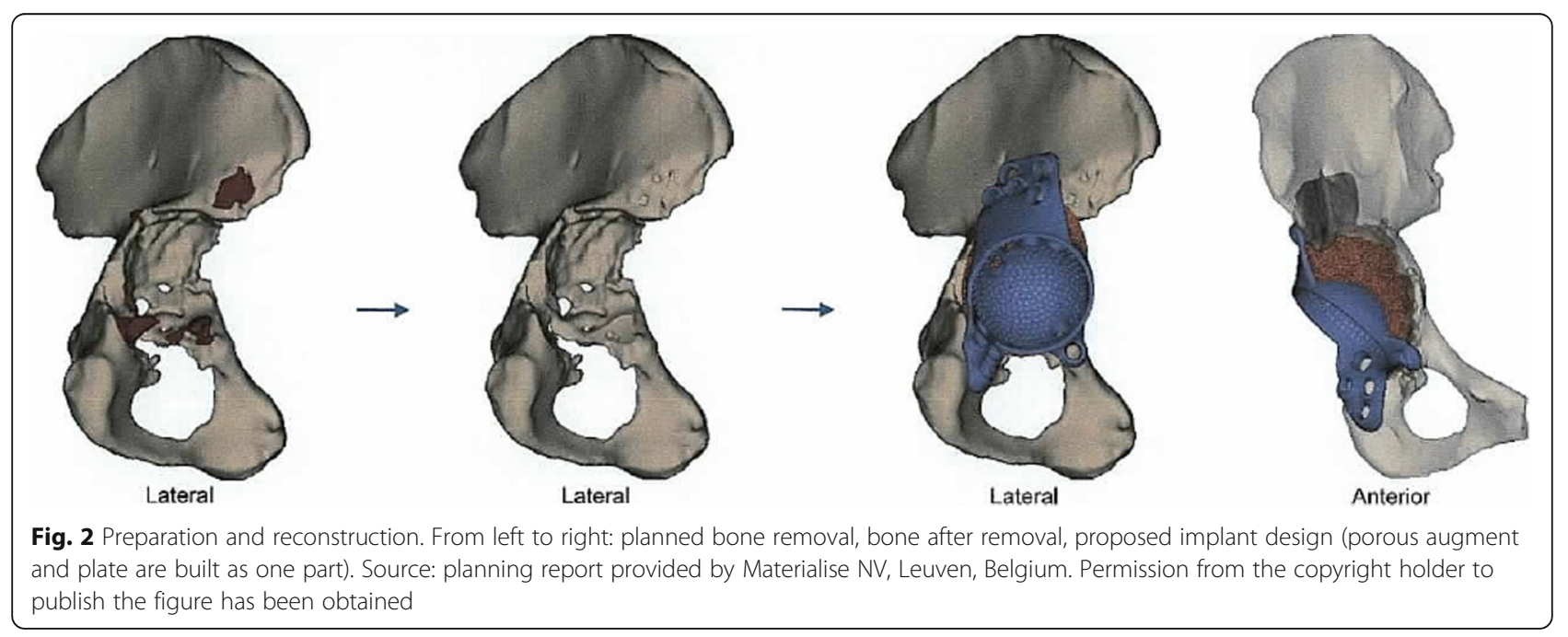


postoperative median: 77, range: 46-92; $\mathrm{n}=9, p=0.01$ ). The patient's abilities, pain and clinical presentations were significantly better after surgery compared to before. HHS improved in every patient (Fig. 3), whereas 8 out of 9 patients experienced improvements in the OHS (Fig. 4).

During surgery, a mean of 9 screws per patient (range 6-12) were used for fixation of the implant. A mean of 13.7 screws per patient (range 12-16) were planned preoperatively according to the bone condition.

Postoperative radiologic follow-up as shown in Fig. 5 showed no significant difference between medial and ilioischial offsets and height of COR in either hip. However, a significant difference in femoral offsets was noticed (Table 3 ). The median anteversion and inclination angles were 17 (range 6-25) and 45 (36-67) degrees, respectively (Table 3 ).

\section{Complications}

Intraoperative microbial samples were positive in one patient who received intravenous antibiotics thereafter. One patient had sciatic nerve palsy due to the intervention. Three of the patients faced postinterventional complications; the patient with sciatic nerve palsy also developed deep vein thrombosis, and two other patients experienced femoroacetabular dislocation. Complications occurred in three over nine patients, resulting in a complication rate of $33.3 \%$. One of these patients underwent a subsequent surgery for changing the type of inlay due to multiple dislocations (re-revision rate, 11.1\%). This intervention led to stable conditions of the hip, and no further dislocations were noticed.

\section{Discussion}

The current study evaluated the functional and radiological outcomes after the use of CTACs in patients with severe acetabular bone defects. Overall, satisfying clinical and radiological outcomes were observed. The OHS and HHS improved significantly one year postoperatively. Our results are comparable to recent research results. In a study by Wind et al., the authors investigated 19 patients after an average follow-up of 31 months after the use of CTACs. The authors found a significantly improved HHS from 38 to 63 points [22]. In another study by Taunton et al., the investigation of 57 patients with pelvic discontinuity at an average of 65 months after the use of CTACs showed a final HHS of 74.8 points [23]. With an average of 10 years, the study with the longest follow-up, performed by DeBoer et al., reported an improvement in the HHS from 41 to 80 points [24]. A recent published systematic review by Chiarlone et al. investigated acetabular custom-made implants for severe acetabular bone defect and showed satisfactory clinical and radiological outcomes at midterm follow-up [25].

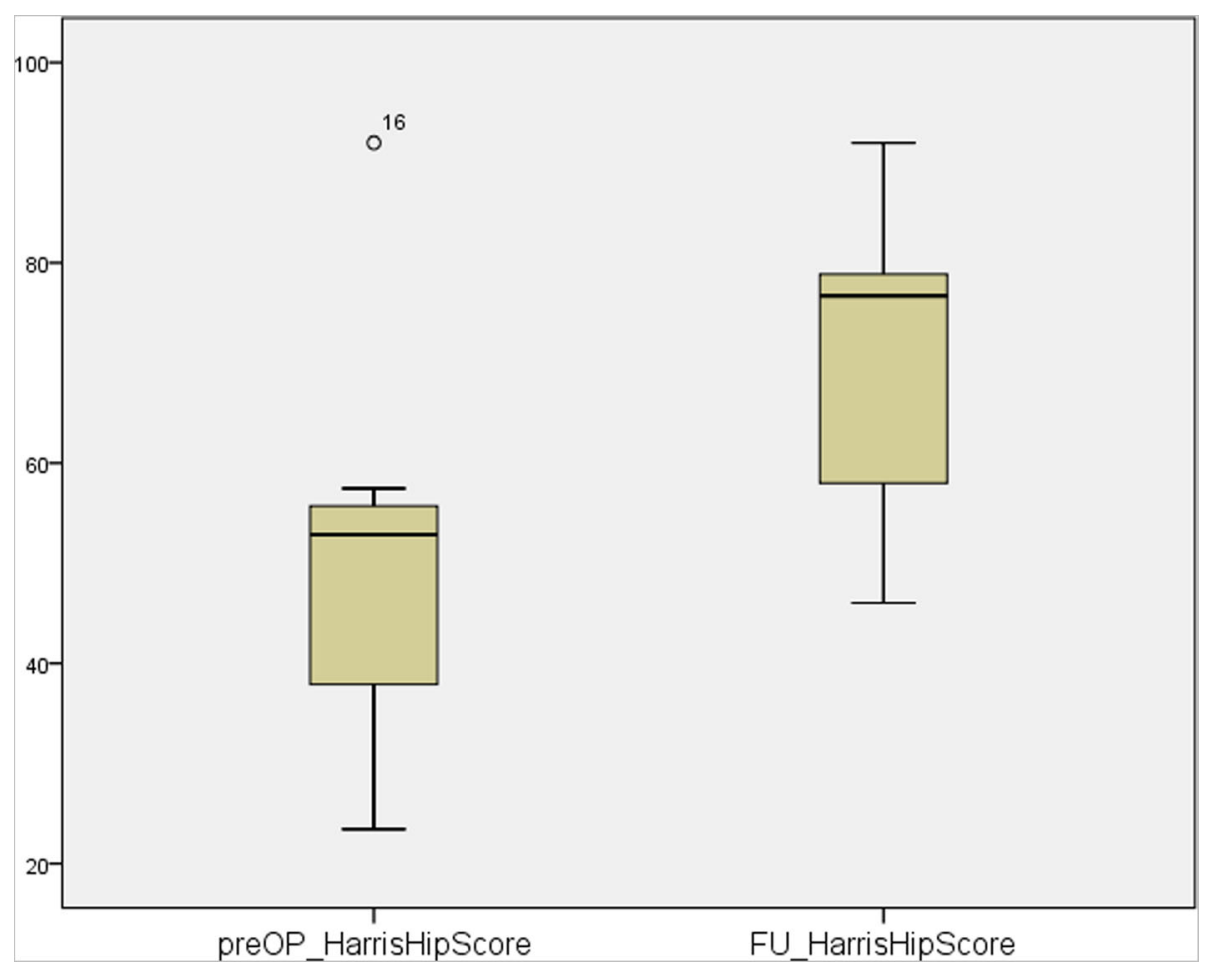

Fig. 3 Pre- vs. postoperative Harris Hip Score 


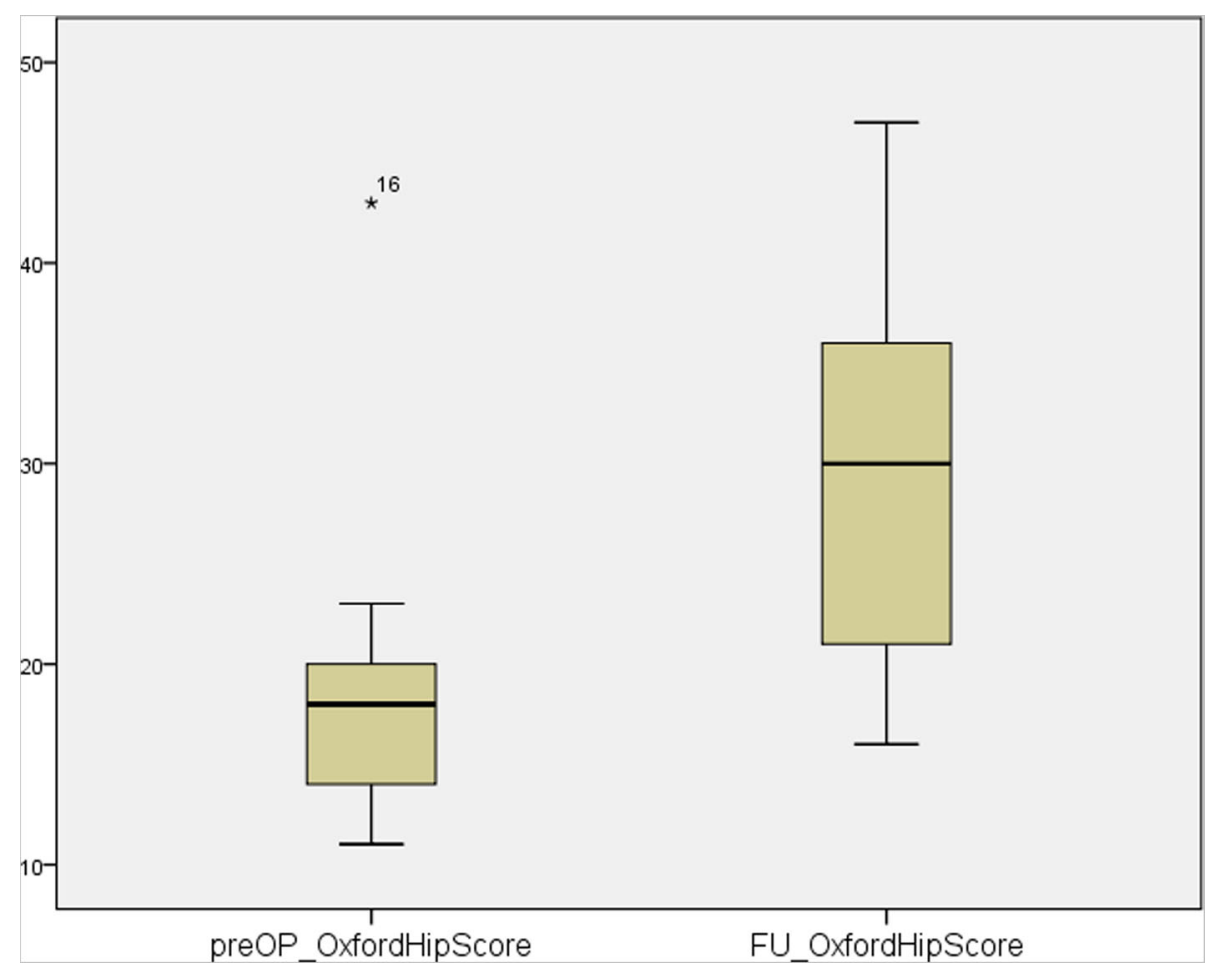

Fig. 4 Pre- vs. postoperative Oxford Hip Score

Radiological measurements of the COR and offsets showed no significant difference when compared to the "healthy" side except femoral offset $(p=0.044)$. However, most of the patients had already received THA on the contralateral side. The current measurements therefore should not be seen as a comparison to baseline data; rather, it shows the correct position of the aMace implant compared to the contralateral hip, regardless of preexisting THA. The significant difference in femoral offset $(p=0.044)$ is most likely due to an increase in medial offset and thus, compensation of global offset with an decrease of femoral offset. However, restoration of the center of rotation is important for postoperative improvement and stability after THA. We achieved this in eight of nine patients with a mean COR of $19.4 \mathrm{~mm}$. A "high hip center of rotation" is defined in the literature with a COR of more than $35 \mathrm{~mm}[12,26]$. Only one patient did not match the limit with a distance to the inter-teardrop line of $38 \mathrm{~mm}$. Durand-Hill et al. reported a $100 \%$ rate of correct implant position as planned preoperatively [27]. However, they did not investigate the position compared to the contralateral side. Others

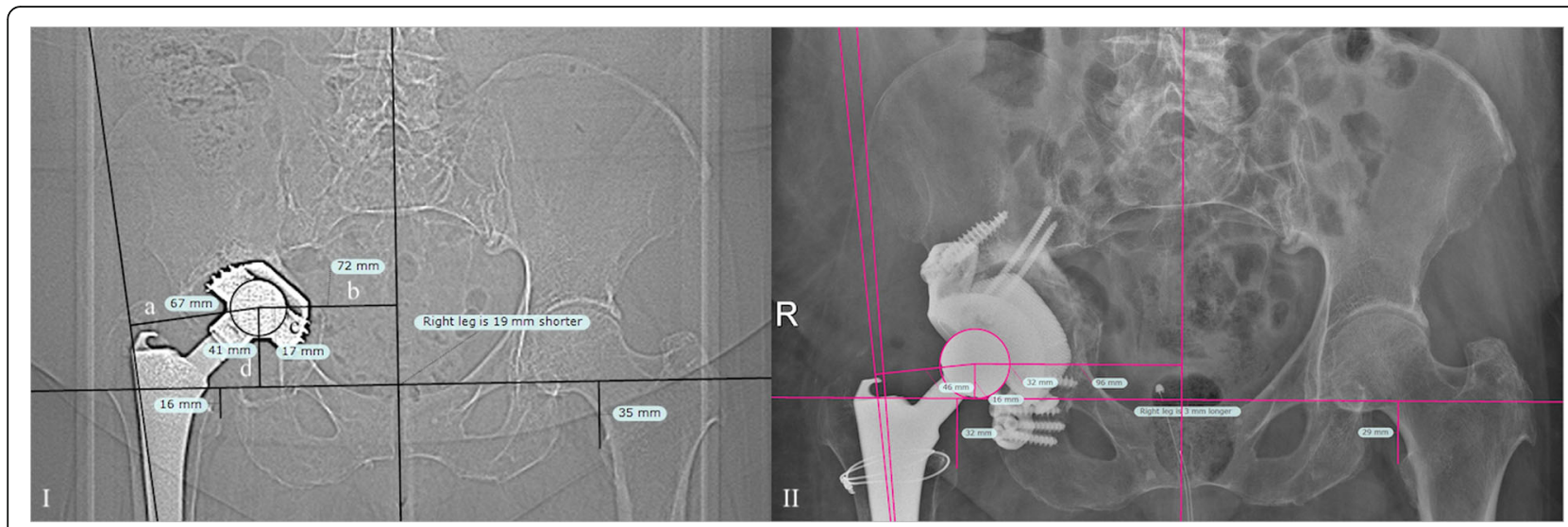

Fig. 5 I) Measurement of offsets in a hip with aseptic loosening (a: femoral offset; $\mathbf{b}$ : medial offset; c: ilioischial offset; d: center of rotation) II) shows the same hip after revision with CTAC 
Table 3 Clinical and radiological results

\begin{tabular}{|c|c|c|c|}
\hline & aMace $(n=9)$ & & \\
\hline Anteversion (deg) & $17(6-25)$ & & \\
\hline \multirow[t]{2}{*}{ Inclination (deg) } & $45(36-67)$ & & \\
\hline & preoperative & postoperative & $p$ \\
\hline Oxford hip score (48) & $18(11-43)$ & $30(16-47)$ & 0.009 \\
\hline \multirow[t]{2}{*}{ Harris hip score (100) } & $53(23-92)$ & $77(46-92)$ & 0.010 \\
\hline & Contralateral side & postoperative & $p$ \\
\hline Femoral offset (mm) & $40(31-54)$ & $34(24-49)$ & 0.044 \\
\hline Medial offset (mm) & $89(78-103)$ & $96(83-120)$ & 0.109 \\
\hline Ilioischial offset (mm) & $27(23-34)$ & $30(12-42)$ & 0.568 \\
\hline Center of rotation (mm) & $17(7-31)$ & $19(3-38)$ & 0.980 \\
\hline
\end{tabular}

Data are presented as the median (range)

reported satisfying final position of the implants, inclination of the shell or osseointegration, but did not investigate offsets and COR [28, 29]. A recently published study by Walter et al. showed significant lateralisation and cranialization when CTAC was used [30]. This study cannot confirm these findings as shown above.

One patient faced postoperative dislocation of the hip 87 days after implantation of the aMace cup. This special case may have been due to too little anteversion, which was 6 degrees in that particular patient. The patient received revision surgery with implantation of a dual mobility cup. No further dislocation was noticed thereafter. None of the other patients experienced postoperative dislocation; in these cases, the anteversion was at a mean of 16.1 degrees.

A review of up-to-date literature shows complications in 16 to $53 \%$ of patients and re-revision in 11 to $35 \%$ $[24,25,31-34]$. We experienced a complication rate of $33.3 \%$, resulting in a re-revision rate of $11.1 \%$, which matched the rates in these trials. None of the implants had to be removed due to postoperative complications.

During surgery, less screws were used to fix the implant (13.7 planned, 9 used). This is mainly due to intersection of some screws, where the surgeon has to select the preferred screw preoperatively. In some additional cases, a screw could not be positioned due to the surgical approach.

Of course, this study has several limitations. The main limitations are the small sample size and the lack of a control group as well as its retrospective design. To achieve a true statement about restoration of COR and offsets, it would need a patient population without arthroplasty on the healthy side. Only retrospective trials are investigating custom made hip cups for severe acetabular defects are available. However, prospectively planned trial would be favourable and should be conducted in the future.

Finally, implant cost is a factor that should be taken into consideration during the decision process. While planning is free of charge, the set of one Materialise aMace implant plus drilling guides and 3D models costs approximately $15.000 €$. In the authors' opinion, the implant is a reasonable alternative for patients with severe acetabular bone defects. However, long-term outcomes still need to be examined, and cost-benefit analysis should be conducted to investigate a potential long-term benefit.

\section{Conclusion}

Revision surgery in THA with Materialise aMace custom-made acetabular components in patients with severe acetabular bone loss shows promising short-term functional and radiological outcomes. However, longterm outcomes still need to be examined.

\section{Abbreviations}

COR: Center of rotation; CRP: C-reactive protein; CT: Computed tomography; CTAC: Custom-made triflanged acetabular components; HHS: Harris Hip Score; IBG: Impaction bone grafting; OHS: Oxford Hip Score; SD: Standard deviation; THA: Total hip arthroplasty; WBC: White blood count

\section{Acknowledgements}

None.

Authors' contributions

MSG was responsible for the collection of the data, the dataset itself as well as the statistical analyses. MSG was also a major contributor in writing the manuscript. MJ was responsible for the collection of data and the follow-up examinations in the Orthopedic Hospital Gersthof. JB was responsible for the acquisition of data and the follow-up examinations in the hospital "Ordensklinikum Linz GmbH Barmherzige Schwestern". JH is the head of orthopedic department at "Ordensklinikum Linz GmbH Barmherzige Schwestern" performed most of the interventions as well as the study design. PR also contributed to the study by performing interventions and was head of the orthopedic department at Orthopedic Hospital Gersthof. RO designed the concept of this study; he was involved in the writing process and corresponds with the journals. All authors read and approved the final manuscript.

\section{Funding}

There was no source of funding or cooperation with the manufacturer whatsoever.

\section{Availability of data and materials}

This manuscript does not contain any individual person's data in any form.

\section{Ethics approval and consent to participate}

This study has been approved by the ethics committee of the hospital "Barmherzige Schwestern Linz" with their chairman Priv.-Doz. Dr. Oleksiy Tsybrovskyy. The number given by the ethics committee is EKS 25/19.

Written consent was provided.

\section{Consent for publication}

No individual person's data are beeing presented.

\section{Competing interests}

To the authors' knowledge, there are no potential competing interests.

\section{Author details}

${ }^{1}$ Unfallkrankenhaus Linz, Linz 4020, Upper Austria, Austria. ${ }^{2}$ Orthopedic Hospital Gersthof, Vienna 1180, Austria. 'Department of Orthopedic Surgery, Ordensklinikum Barmherzige Schwestern Linz, Vinzenzgruppe Center of Orthopedic Excellence, Teaching Hospital of the Paracelsus Medical University Salzburg, Linz 4020, Austria. ${ }^{4}$ Institute for Sports Medicine, Alpine Medicine and Health Tourism (ISAG), Tirol Kliniken $\mathrm{GmbH}$, Innsbruck and UMIT, Hall Austria, Innsbruck 6020, Tyrol, Austria. 
Received: 22 June 2020 Accepted: 1 December 2020

Published online: 10 December 2020

\section{References}

1. Inacio MCS, Graves SE, Pratt NL, Roughead EE, Nemes S. Increase in Total joint Arthroplasty projected from 2014 to 2046 in Australia: a conservative local model with international implications. Clin Orthop Relat Res. 2017; 475(8):2130-7.

2. Skyttä ET, Jarkko L, Antti E, Huhtala H, Ville R. Increasing incidence of hip arthroplasty for primary osteoarthritis in 30- to 59-year-old patients. Acta Orthop. 2011;82(1):1-5 Available from: http://www.tandfonline.com/doi/ full/10.3109/17453674.2010.548029.

3. Pabinger $C$, Geissler A. Utilization rates of hip arthroplasty in OECD countries. Osteoarthr Cartil. 2014;22(6):734-41. Available from:. https://doi. org/10.1016/j.joca.2014.04.009.

4. Bozic KJ, Kamath AF, Ong K, Lau E, Kurtz S, Chan V, et al. Comparative epidemiology of revision Arthroplasty: failed THA poses greater clinical and economic burdens than failed TKA. Clin Orthop Relat Res. 2015;473(6):21318. Available from:. https://doi.org/10.1007/s11999-014-4078-8.

5. Baauw M, van Hooff ML, Spruit M. Current Construct Options for Revision of Large Acetabular Defects. JBJS Rev. 2016;4(11):1 Available from: http:// insights.ovid.com/crossref?an=01874474-201611000-00001.

6. Hastings DE, Parker SM. Protrusio acetabuli in rheumatoid arthritis. Clin Orthop Relat Res [Internet]. 1975 May;66(108):76-83. Available from: http:// www.ncbi.n/m.nih.gov/pubmed/1139840.

7. Schreurs BW, te Stroet MAJ, Rijnen WHC, Gardeniers JWM. Acetabular rerevision with impaction bone grafting and a cemented polyethylene cup; a biological option for successive reconstructions. HIP Int. 2015;25(1):44-9 Available from: http://journals.sagepub.com/doi/10.5301/hipint.5000193.

8. Wilson MJ, Whitehouse SL, Howell JR, Hubble MJW, Timperley AJ, Gie GA. The results of Acetabular impaction grafting in 129 primary cemented Total hip Arthroplasties. J Arthroplasty [Internet]. 2013;28(8):1394-400. Available from. https://doi.org/10.1016/j.arth.2012.09.019.

9. Pulido L, Rachala SR, Cabanela ME. Cementless acetabular revision: past, present, and future. Int Orthop. 2011;35(2):289-98 Available from: http://link. springer.com/10.1007/s00264-010-1198-y.

10. Ibrahim MS, Raja S, Haddad FS. Acetabular impaction bone grafting in total hip replacement. Bone Joint J. 2013;95-B(11_Supple_A):98-102 Available from: http://online.boneandjoint.org.uk/doi/10.1302/0301-620X.95B11.32834.

11. Paprosky WG, Perona PG, Lawrence JM. Acetabular defect classification and surgical reconstruction in revision arthroplasty. A 6-year follow-up evaluation. J Arthroplast. 1994;9(1):33-44.

12. Whitehouse MR, Masri BA, Duncan CP, Garbuz DS. Continued good results with modular trabecular metal augments for Acetabular defects in hip Arthroplasty at 7 to 11 years. Clin Orthop Relat Res. 2015;473(2):521-7 Available from: http://link.springer.com/10.1007/s11999-014-3861-x.

13. Martin JR, Barrett I, Sierra RJ, Lewallen DG, Berry DJ. Construct Rigidity: Keystone for Treating Pelvic Discontinuity. J Bone Jt Surg. 2017;99(9):e43 Available from: http://insights.ovid.com/crossref?an=00004623-20170503000012.

14. Kinov P, Tivchev P. Revision Hip Arthroplasty: Management of Bone Loss. In: Arthroplasty - Update [Internet]. InTech; 2013. Available from: http://www. intechopen.com/books/arthroplasty-update/revision-hip-arthroplastymanagement-of-bone-loss.

15. Issack PS, Nousiainen M, Beksac B, Helfet DL, Sculco TP, Buly RL. Acetabular component revision in total hip arthroplasty. Part II: management of major bone loss and pelvic discontinuity. Am J Orthop (Belle Mead NJ). 2009;38(11): 550-6 Available from: http://www.ncbi.nlm.nih.gov/pubmed/20011740.

16. Myncke I, van Schaik D, Scheerlinck T. Custom-made triflanged acetabular components in the treatment of major acetabular defects. Short-term results and clinical experience. Acta Orthop Belg. 2017;83(3):341-50 Available from: http://www.actaorthopaedica.be/acta/download/2017-3/01Myncke.pdf.

17. Malik HH, Darwood ARJ, Shaunak S, Kulatilake P, El-Hilly AA, Mulki O, et al. Three-dimensional printing in surgery: a review of current surgical applications. J Surg Res. 2015;199(2):512-22 Available from: https:// linkinghub.elsevier.com/retrieve/pii/S0022480415007295.

18. Eltorai AEM, Nguyen E, Daniels AH. Three-Dimensional Printing in Orthopedic Surgery. Lindeque BGP, editor. Orthopedics. 2015;38(11):684-7 Available from: http://www.healio.com/doiresolveer?doi=10.3928/0147744 7-20151016-05.
19. Telleria JJM, Gee AO. Classifications in brief: Paprosky classification of Acetabular bone loss. Clin Orthop Relat Res. 2013:471(11):3725-30 Available from: http://link.springer.com/10.1007/s11999-013-3264-4.

20. Dawson J, Fitzpatrick R, Carr A, Murray D. Questionnaire on the perceptions of patients about total hip replacement. J Bone Joint Surg Br. 1996;78-B(2): 185-90 Available from: http://online.boneandjoint.org.uk/doi/10.1302/03 01-620X.78B2.0780185.

21. Banaszkiewicz PA. Traumatic arthritis of the hip after dislocation and Acetabular fractures: treatment by Mold Arthroplasty: an end-result study using a new method of result evaluation. In: Banaszkiewicz PA, Kader DF, editors. Classic papers in Orthopaedics [Internet]. London: Springer London; 2014. p. 13-7. Available from: http://link.springer.com/10.1007/978-1-44 71-5451-8.

22. Wind MA, Swank ML, Sorger JI. Short-term results of a custom Triflange Acetabular component for massive Acetabular bone loss in revision THA. Orthopedics [Internet]. 2013;36(3):e260-5 Available from: http://www.healio. com/doiresolver?doi=10.3928/01477447-20130222-11.

23. Taunton MJ, Fehring TK, Edwards P, Bernasek T, Holt GE, Christie MJ. Pelvic discontinuity treated with custom Triflange component: a reliable option. Clin Orthop Relat Res [Internet]. 2012;470(2):428-34 Available from: http:// link.springer.com/10.1007/s11999-011-2126-1.

24. DeBoer DK, Christie MJ, Brinson MF, Morrison JC. Revision Total hip Arthroplasty for pelvic discontinuity. J Bone Jt Surg [Internet]. 2007;89(4): 835-40 Available from: http://insights.ovid.com/crossref?an=00004623-2 00704000-00020.

25. Chiarlone F, Zanirato A, Cavagnaro L, Alessio-Mazzola M, Felli L, Burastero G. Acetabular custom-made implants for severe acetabular bone defect in revision total hip arthroplasty: a systematic review of the literature. Arch Orthop Trauma Surg. 2020;140(3):415-24. Available from. https://doi.org/10. 1007/s00402-020-03334-5.

26. Antoniades J, Pellegrini VD. Cross-sectionalanatomy of the ilium: implications for acetabular component placement in total hip arthroplasty. Clin Orthop Relat Res. 2012;470(12):3537-41.

27. Durand-Hill M, Henckel J, Di Laura A, Hart AJ. Can custom 3D printed implants successfully reconstruct massive acetabular defects? A 3D-CT assessment. J Orthop Res. 2020;44(0):jor.24752. Available from:. https://doi. org/10.1002/jor.24752.

28. Aprato A. Management of Paprosky type three B acetabular defects by custom-made components : early results. Int Orthop 2019:43(1):117-22.

29. Burastero G, Cavagnaro L, Chiarlone F, Zanirato A, Mosconi L, Felli L, et al. Clinical study of outcomes after revision surgery using porous titanium custom-made implants for severe acetabular septic bone defects. Int Orthop. 2020:44(10):1957-64.

30. Walter SG, Randau TM, Gravius N, Gravius S, Fröschen FS. Monoflanged custom-made Acetabular components promote biomechanical restoration of severe Acetabular bone defects by metallic defect reconstruction. Arthroplasty. 2020;35(3):831-5. Available from. https://doi.org/10.1016/j.arth. 2019.10.040.

31. Holt G, Dennis D. Use of custom Triflanged Acetabular components in revision Total hip Arthroplasty. Clin Orthop Relat Res. 2005:429:209-14.

32. Joshi AB, Lee J, Christensen C. Results for a custom acetabular component for acetabular deficiency. J Arthroplasty. 2002;17(5):643-8 Available from: https://linkinghub.elsevier.com/retrieve/pii/S0883540302000621.

33. Taunton MJ, Fehring TK, Edwards P, Bernasek T, Holt GE, Christie MJ. Pelvic discontinuity treated with custom triflange component: a reliable option. Clin Orthop Relat Res. 2012;470(2):428-34.

34. Wind MA, Swank ML, Sorger JI. Short-term results of a custom triflange acetabular component for massive acetabular bone loss in revision THA. Orthopedics. 2013:36(3):260-5.

\section{Publisher's Note}

Springer Nature remains neutral with regard to jurisdictional claims in published maps and institutional affiliations. 